\title{
Fine structure of the male reproductive ducts, vagina and seminal receptacle of Cyathocephalus truncatus (Cestoda: Spathebothriidea)
}

\author{
Larisa G. Poddubnaya ${ }^{1}$, John S. Mackiewicz ${ }^{2}$, Magdaléna Bruňanská ${ }^{3,4}$ and Bahram S. Dezfuli ${ }^{5}$ \\ ${ }^{1}$ Institute of Biology of Inland Waters, Russian Academy of Sciences, 152742 Borok, Yaroslavl Province, Russia; \\ ${ }^{2}$ Department of Biological Sciences, State University of New York, Albany, NY 12222, USA; \\ ${ }^{3}$ Institute of Parasitology, Academy of Sciences of the Czech Republic, Branišovská 31, 37005 České Budějovice, Czech \\ Republic; \\ ${ }^{4}$ Parasitological Institute, Slovak Academy of Sciences, Hlinkova 3, 04001 Košice, Slovakia; \\ ${ }^{5}$ Department of Biology, University of Ferrara, St. Borsari, 46, 44100 Ferrara, Italy
}

Key words: Cyathocephalus truncatus, ultrastructure, male ducts, accessory glands, vagina, seminal receptacle

\begin{abstract}
Fine structure of the vas efferens, vas deferens, ejaculatory duct with accessory glands and vagina with seminal receptacle is described in the spathebothriidean tapeworm, Cyathocephalus truncatus (Pallas, 1781) Kessler, 1868. The numerous well-developed prostate glands are characterised by having secretory granules with an electron-dense core surrounded by a matrix of lower electron density. Coalescence of the outer part of the granules with each other takes place in the terminal end of the secretory ducts. The position of prostate glands around the proximal part of the cirrus pouch and terminating in the ejaculatory duct is a characteristic feature of the Spathebothriidea. Up to 20 closely arranged muscle layers make up the muscular cirrus pouch wall with 4 well-developed muscular layers in the ejaculatory duct and cirrus. Both the cirrus and the vagina are covered with the same uniform cone-shaped microtriches. The vagina has an extensive seminal receptacle. All of these structures are well-adapted to insure successful sperm transfer involving ejaculation and storage, probably for both self- and cross-insemination. Cyathocephalus truncatus has a cirrus similar to that of the monozoic, progenetic caryophyllidean, Archigetes sieboldi and well-developed prostate glands like those of the polyzoic pseudophyllidean, Diphyllobothrium latum. The ultrastructural aspects of the male and female reproductive system of $C$. truncatus are compared with those of other tapeworms.
\end{abstract}

The Spathebothriidea is a small group of polyzoic tapeworms with a polypleuroid body type, that is, with proglottization but no defined segments (Mackiewicz 2003). This lack of segmentation has been explained as either secondarily derived from a strobilate tapeworm (Fuhrmann 1931, Joyeux and Baer 1961, Protasova and Roytman 1995), or ancestral to the monozoic caryophyllideans (Nybelin 1922, Olson and Caira 1999). However, the non-segmented but polyzoic spathebothriideans and monozoic caryophyllideans have been determined to represent the ancestral condition and occupy a basal position on the cestode evolutionary tree (Mariaux 1998, Hoberg et al. 2001, Mariaux and Olson 2001, Olson et al. 2001). It is clear that the systematic position and relationship of the Spathebothriidea to other cestodes is far from resolved.

There is no modern, detailed treatment of the Spathebothriidea (Gibson 1994). Most of the information on the group deals with aspects of general biology, morphology or taxonomy (Nybelin 1922, Wardle and McLeod 1952, Gibson 1994, Protasova and Roytman 1995, Kearn 1998, Okaka 2000). Little information is available on the anatomy and morphology at the ultrastructural level for any species. Ultrastructural observations on genital organs of members of the Spathe- bothriidea is limited to the study of uterine and prostate glands in progenetic Diplocotyle olrikii (Davydov et al. 1997) and the structure of spermatozoa in Bothrimonus sturionis (MacKinnon and Burt 1984). The present contribution describes the fine structure of the male ducts with accessory glands and vagina with seminal receptacle of the female system in Cyathocephalus truncatus (Pallas, 1781) Kessler, 1868. Detailed morphological data of the reproductive system may help in the analysis of interrelationships of the Spathebothriidea among the lower tapeworms.

\section{MATERIALS AND METHODS}

Adult Cyathocephalus truncatus were recovered from the pyloric appendices of two salmonid fish species, grayling (Thymallus arcticus baicalensis Dybowski) from Lake Baikal (Russia), and brown trout (Salmo trutta) from Carmigniano of Brenta (province of Padua, North Italy). The worms from Lake Baikal were cut into small pieces and fixed in 3\% glutaraldehyde in $0.1 \mathrm{M}$ phosphate buffer $\left(\mathrm{pH} \mathrm{7.4)}\right.$ ) for $6 \mathrm{~h}$ at $4^{\circ} \mathrm{C}$. They were postfixed in $1 \%$ osmium tetroxide in $0.1 \mathrm{M}$ phosphate buffer for $1 \mathrm{~h}$ at $4{ }^{\circ} \mathrm{C}$. The worms from Italy were fixed in $2 \%$ glutaraldehyde in $0.1 \mathrm{M}$ sodium cacodylate buffer $(\mathrm{pH}$ 7.2 ) for $3.5 \mathrm{~h}$ at $4^{\circ} \mathrm{C}$. Postfixation followed in $1 \%$ osmium tetroxide in $0.1 \mathrm{M}$ cacodylate buffer for $2 \mathrm{~h}$ at $4{ }^{\circ} \mathrm{C}$. The mate- 
rial was dehydrated in a graded series of acetone and embedded in Araldite or in Epon. Semithin sections were cut on a Reichert ultramicrotome, stained with methylene blue and examined under a light microscope for identification of different male ducts. Ultrathin sections were stained with uranyl acetate and lead citrate. They were examined in a JEM-100 C transmission electron microscope operating at $60 \mathrm{kV}$.

\section{RESULTS}

The male reproductive system of $C$. truncatus consists primarily of numerous sets of testes that extend in two irregular lateral medullary bands throughout the length of the body. Each testis leads into the fine ducts, the vas efferens (Fig. 1). Vasa efferentia are interconnected and become united into a common duct, the vas deferens (Fig. 2). The convoluted vas deferens enters the cirrus pouch, where it is modified into the ejaculatory duct (Figs. 3, 4, 8). The ejaculatory duct is directly associated with the prostate glands through the gland openings. The distal part of the ejaculatory duct is further on modified into the male copulatory organ, cirrus (Figs. 5-8), which can be functional through the cirrus pore.

\section{Vas efferens}

The ducts of the vasa efferentia are built up of syncytial anucleate epithelium approximately $0.27 \mu \mathrm{m}$ thick, which is underlined by a basal membrane and by a fibrillar layer of basal lamina (Fig. 1). The apical membrane of the duct has short lamellae up to $0.7 \mu \mathrm{m}$ long. The cytoplasm of syncytial epithelium contains abundant free ribosomes.

\section{Vas deferens}

Compact loops of the vas deferens have a voluminous lumen filled with spermatozoa (Fig. 2). The lining of the vas deferens possesses numerous sinuous apical lamellae. The wall of this duct is composed of a thin epithelium layer that is supported by the folded basal membrane. The epithelium consists of syncytial nucleate cytoplasm, rich in free ribosomes. The large nuclei contain distinct nucleoli and aggregation of peripheral heterochromatin. Two layers of circular and longitudinal myofibrils are situated under the basal membrane.

\section{Ejaculatory duct and prostate glands}

The wall of the ejaculatory duct consists of a thin syncytial layer lined by basal lamina (Figs. 3, 4, 8, 14). The syncytium contains nuclei that are large and situated near the basal membrane within the proximal part of the ejaculatory duct (Figs. 3,8) and more distinct and prominent in the distal part (Figs. 4, 8). The apical membrane of the duct is modified into long sinuous lamellae. Four layers of circular and longitudinal myofibrils are arranged under the basal lamina of the syncytium. Spermatozoa occur frequently within the lumen of the ejaculatory duct (Figs. 3, 8, 14, 15).

The numerous unicellular prostate glands are grouped near the cirrus pouch (Fig. 8). The cytoplasm of each gland cell is rich in ribosomes and granular endoplasmic reticulum (Figs. 9, 10) and numerous secretory granules of different size (from $0.24 \mu \mathrm{m}$ up to $0.88 \mu \mathrm{m}$ in diameter) are aggregated near the nuclei of the cytons (Figs. 8-11). These secretory granules have a distinct, round electron-dense core within an outer matrix of lower electron density (Fig. 11). The long projections of the gland cells extend into the parenchyma that surrounds the cirrus sac and pass between the muscle layers of the cirrus sac wall to the ejaculatory duct (Figs. 3, 8, 12). Before entering the ejaculatory duct, the walls of the gland cell projections are strengthened by peripheral microtubules and the projections become ducts (Fig. 13). Secretory granules can be seen tightly packed inside the glandular ducts (Figs. 13, 16, 17). These ducts then pass through the muscle layers beneath the syncytial epithelium of the ejaculatory duct, continue through the epithelium and pass into the lumen of the ejaculatory duct (Figs. 14, 15) where they remain closed (Fig. 8) until the granules are released into the lumen. Once released, these granules burst their limiting membranes and release their secretory products (Fig. 17) to coalesce and surround the spermatozoa (Figs. 14, 15).

\section{Cirrus}

Before becoming the cirrus, the syncytial epithelium of the ejaculatory duct loses surface apical lamellae and cytons and is packed with small electron-dense bodies (Figs. 4, 8). The cirrus is a muscular duct that is covered from inside with an anucleate, syncytial epithelium (Figs. 5-8). Epithelium of the proximal region of the cirrus near the ejaculatory duct is thinner $(0.60 \pm 0.04$ $\mu \mathrm{m})$ than that of the distal region $(1.04 \pm 0.07 \mu \mathrm{m})$. The apical surface of the epithelium is covered with numerous microtriches of the cone-shaped type (Figs. 7, 8). The base of the microtriches is $0.35 \pm 0.04 \mu \mathrm{m}$ long and approximately $0.12 \mu \mathrm{m}$ wide; shafts are electron-dense in the proximal part of the cirrus and are $0.78 \pm 0.15 \mu \mathrm{m}$ long (Fig. 7). Some of the microtriches in the distal part of the cirrus have electron-lucent shafts up to $1.56 \mu \mathrm{m}$ long (Figs. 5, 8). Well-developed muscle layers continuous with those of the ejaculatory duct support the cirrus (Figs. 6, 8).

\footnotetext{
Figs. 1-7. Different types of male reproductive ducts of Cyathocephalus truncatus. Fig. 1. Syncytial anucleate epithelium of vas efferens. Fig. 2. The wall of vas deferens with large nucleus. Fig. 3. The nucleate epithelium of ejaculatory duct supported by muscle layer. Fig. 4. The junction of the ejaculatory duct and cirrus. Fig. 5. Microtriches of distal part of cirrus. Fig. 6. Syncytial epithelium of cirrus and four layers of muscles. Fig. 7. Microtriches of proximal part of cirrus. Abbreviations: BM - basal membrane; $\mathrm{C}$ - cirrus; DB - dense bodies; DM - distal part of microtriches; ED - ejaculatory duct; FBM - folded basal membrane; L - lamellae; LS - sinuous lamellae; ML - muscle layers; MT - microtriches; N - nucleus; PG - projection of the prostate glands; PPM - proximal part of microtriches; SE - syncytial epithelium; SP - spermatozoa. Scale bars: Figs. 1, $2=0.5 \mu \mathrm{m}$; Figs. $3,4=2 \mu \mathrm{m}$; Figs. $5,7=0.2 \mu \mathrm{m}$; Fig. $6=3 \mu \mathrm{m}$.
} 


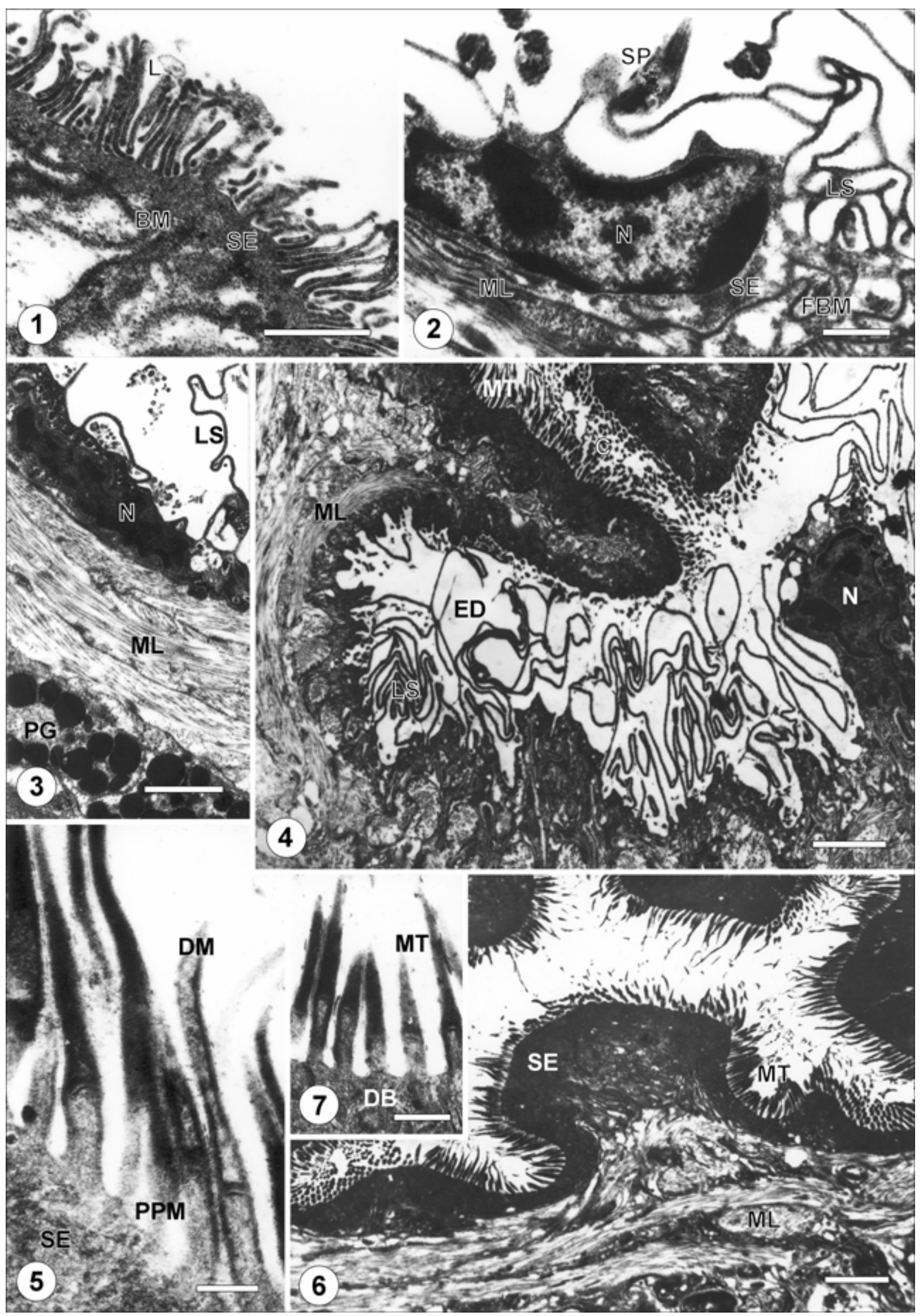




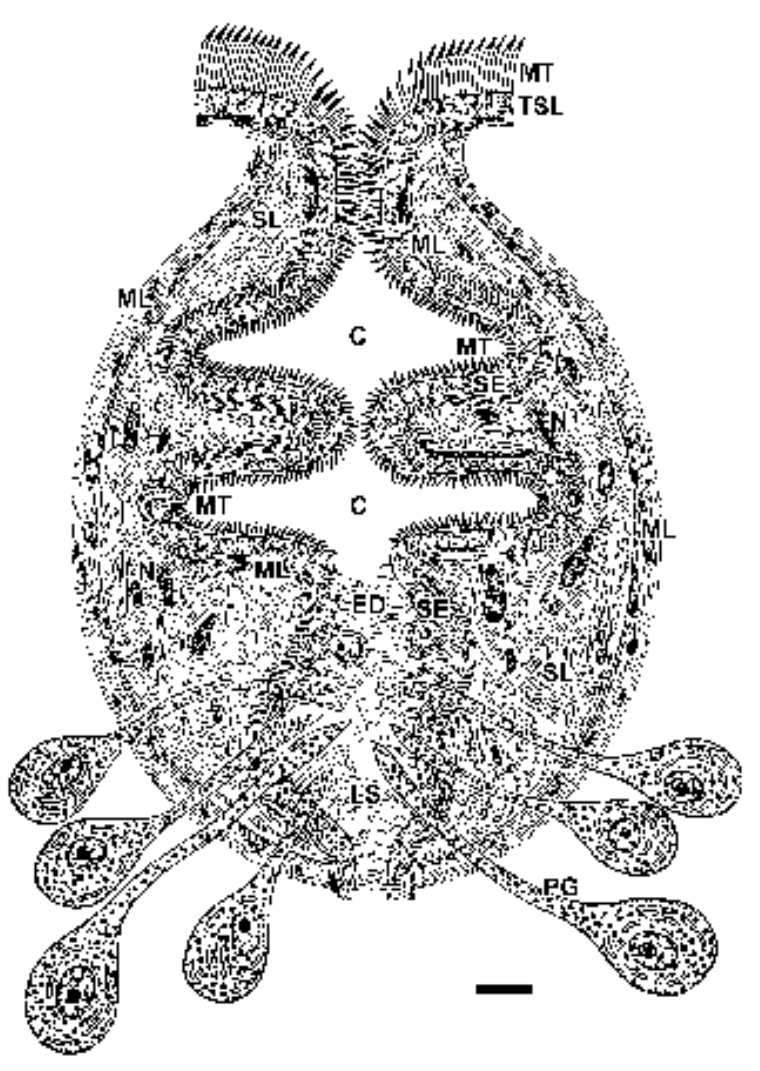

Fig. 8. Schematic drawing of cirrus pouch of Cyathocephalus truncatus. Abbreviation: C - cirrus; ED - ejaculatory duct; LS - sinuous lamellae; ML - muscle layers; MT - microtriches; $\mathrm{N}$ - nucleus; PG - projection of the prostate glands; SE syncytial epithelium; SL - sarcoplasma-like lamellae; TSL tegument syncytial layer. Scale bar $=2 \mu \mathrm{m}$.

\section{Cirrus pouch}

The wall of the cirrus pouch, up to $17 \mu \mathrm{m}$ thick, contains 15-20 closely arranged circular and longitudinal muscle layers (Figs. 8, 12, 18). In addition, numerous myocytons and projections of the prostate glands are localised in the muscular cirrus pouch wall (Figs. 12, 18). The myocytons within the cirrus pouch have long, narrow processes of sarcoplasma-like lamellae that fill the cirrus pouch (Fig. 19).

\section{Vagina}

The syncytial anucleate epithelium of vagina is $1.8 \pm$ $0.1 \mu \mathrm{m}$ thick in the distal portion and $0.97 \pm 0.17 \mu \mathrm{m}$ thick in the proximal portion (Figs. 20, 22). The distal vagina wall is lined by microtriches that have bases 0.32 $\pm 0.06 \mu \mathrm{m}$ long and an electron-dense part $0.64 \pm 0.03$ $\mu \mathrm{m}$ long (Fig. 21). Microtriches on the proximal portion are smaller (Fig. 22). The epithelial cytoplasm of the distal part has abundant electron-dense bodies, free ribosomes, and mitochondria. Muscles consist of two layers of myofibrils adjacent to the epithelium in the proximal portion of the vagina and four layers in the distal part (Figs. 20, 22). Spermatozoa can often be found within the lumen of the vagina (Fig. 22).

\section{Seminal receptacle}

A large seminal receptacle, often filled with spermatozoa, is present at the end of the proximal vagina (Figs. 23-25). The thin distal lining is composed of a matrix containing numerous free ribosomes, mitochondria, and profiles of granular endoplasmic reticulum (Fig. 23). The syncytial lining has numerous large, basal nuclei (Fig. 25). The epithelial wall is vesiculate, with abundant electron-lucid vesicles near nucleus (Fig. 25). The apical membrane is deeply folded and has numerous sinuous lamellae (Fig. 23). Seminal receptacle myofibrils are arranged as a single muscle layer and form the sarcoplasma-like lamellae (Fig. 24).

\section{DISCUSSION}

Our observations at the ultrastructural level help to add further details to the light microscope description of the cirrus complex, vagina and seminal receptacle by Protasova and Roytman (1995). For example, (1) there are up to 20 closely arranged muscle layers making up the muscular cirrus pouch wall, (2) the apical surface of the proximal region of the cirrus has small cone-shaped microtriches with electron-dense shafts while the distal region has a mixture of more elongate microtriches with electron-dense and electron-lucent shafts, and (3) the proximal part of the cirrus and distal part of vagina are similar to each other, being lined by the same kind of microtriches and underlined by four layers of muscles. On the other hand, we did not confirm the presence of gland cells around the seminal receptacle, nor a distinct internal seminal vesicle nor a sphincter between the ejaculatory duct and cirrus as described by Protasova and Roytman (1995). In this regard, our observations corroborate those of Nybelin (1922). There is, nevertheless, a pronounced difference in the structure of the epithelium of the ejaculatory duct and cirrus: the ejaculatory duct has a syncytial epithelium with conspicuous cytons and apical lamellae while the cirrus has an epithelium with small electron-dense bodies and apical microtriches. Both structures are supported by four well-developed muscular layers. The large seminal receptacle has numerous epithelium cytons located basally.

Figs. 9-14. The prostate glands of Cyathocephalus truncatus. Fig. 9. Cyton of prostate gland. Fig. 10. Organelles of prostate gland cytoplasm. Fig. 11. Morphology of secretory prostate granules. Fig. 12. Projection of gland cell between muscle layers of cirrus sac wall. Fig. 13. Ducts of the prostate glands. Fig. 14. Section through part of ejaculatory duct. Abbreviations: DC - dense core; GER - granular endoplasmic reticulum; LS - sinuous lamellae; MG - outer matrix of lower electron density of secretory granules; ML - muscle layers; $\mathrm{N}$ - nucleus; PD - prostate ducts; PG - projection of the prostate glands; PM - peripheral microtubules; R - free ribosomes; SE - syncytial epithelium; SG - secretory granules; SP - spermatozoa. Scale bars: Figs. $9,14=1$ $\mu \mathrm{m}$; Fig. $10=0.2 \mu \mathrm{m}$; Figs. $11,13=0.5 \mu \mathrm{m}$; Fig. $12=2 \mu \mathrm{m}$. 


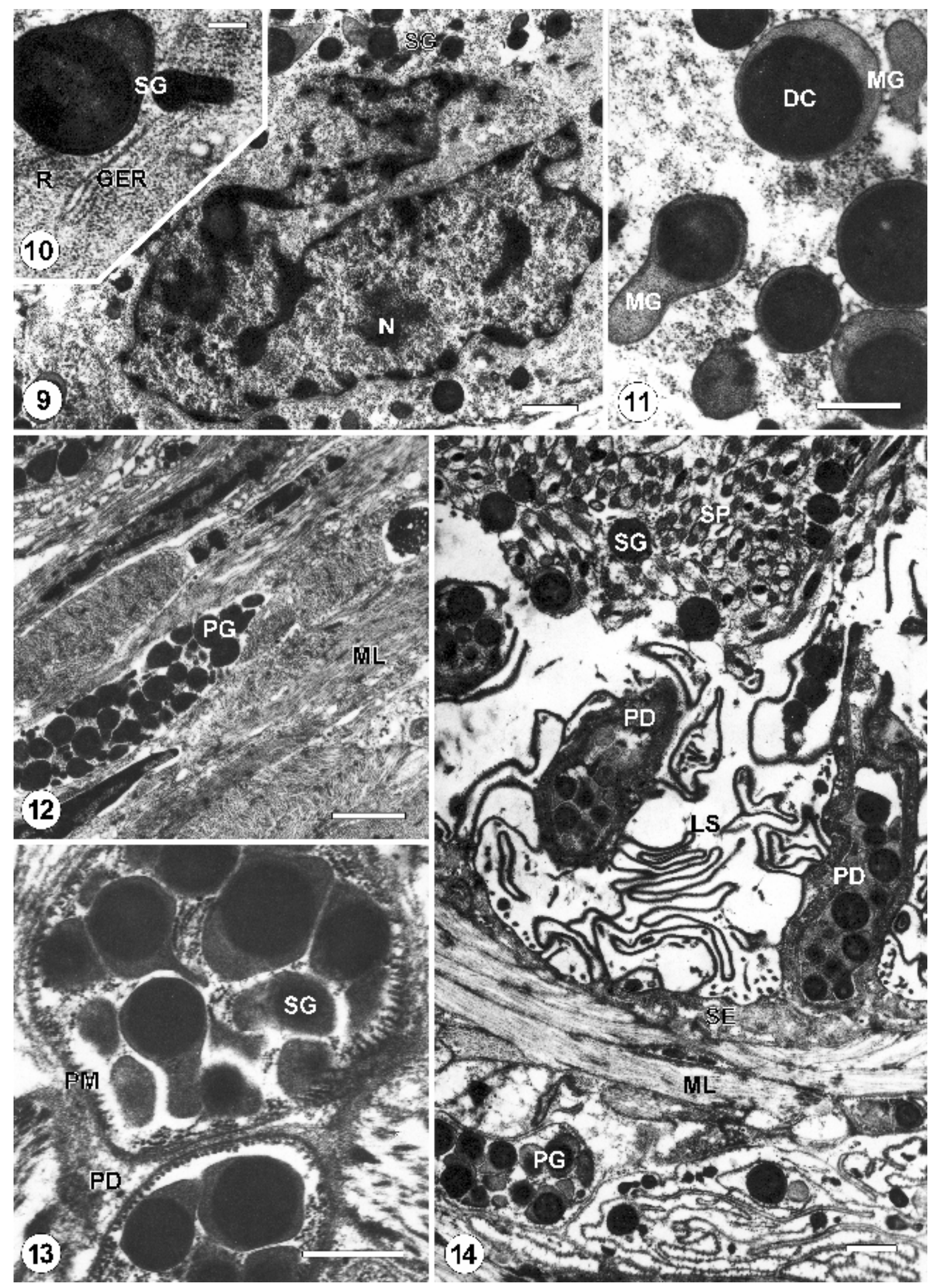


Well-developed prostate glands around the proximal part of the cirrus pouch that open into the ejaculatory duct appear to be a characteristic of the Spathebothriidea. Such glands were earlier described from Cyathocephalus, Bothrimonus and Diplocotyle by Nybelin (1922). Our work on C. truncatus confirms the observation of Davydov et al. (1997) on Diplocotyle olrikii that the ultrastructural morphology of these prostate glands shares most of the features of similar glands of other tapeworms. All are specialised unicellular glands that consist of a cell body tapering into a system of projections that become ducts opening either into the lumen of the ejaculatory duct (Davydov et al. 1997, Korneva and Davydov 2001, Poddubnaya 2002, present study), or into the vas deferens near the cirrus sac (Jones 1994, Poddubnaya 2002, 2003a), or into the cirrus itself (Coil 1970).

The ultrastructure of the prostate secretory granules of $C$. truncatus are similar to those of another spathebothriidean, D. olrikii (Davydov et al. 1997). Most of these granules in $C$. truncatus have a round electrondense core surrounded by a matrix of lower electron density, similar to the prostate secretory granules of the monogenean Diclidophora merlangi (Halton and Hardcastle 1977). These authors reported that the secretion of these glands in Diclidophora possibly functions to stimulate spermatozoa, activate the female reproductive tract during copulation and facilitate the process of copulation. The present study shows clearly that the outer, less electron-dense part of the secretory granules coalesces to form a matrix in the terminal end of the secretory ducts. We can speculate that such coalescence of secretory products within the ejaculatory duct may provide spermatozoa with a protective coating, stimulate swimming action of the spermatozoa and facilitate insemination. We detected no secretory granules within any part of the vagina. The preceding observations suggest that, as in the monogenea, secretions of the prostate glands may play an important role during copulation of cestodes.

The only cestode species with well-developed prostate glands comparable to those of $C$. truncatus appears to be Diphyllobothrium latum of the Pseudophyllidea (Poddubnaya 2002). The common features of the glands in both species are the numerous cells and their termination in the ejaculatory duct. The position of the prostate glands varies in these tapeworms, however in D. latum they are within the cirrus pouch, whereas in $C$. truncatus they are away from it in the parenchyma. This latter arrangement appears to be a characteristic feature of the Spathebothriidea. On the other hand, prostate glands may be in the middle part of the vas deferens of D. latum (Poddubnaya 2002), distal part of the vas deferens of Eubothrium rugosum (Poddubnaya 2003a), or at the sperm duct just before the cirrus sac of Cylindrotaenia hickmani (Jones 1994). In all of these cases, discharge of the secretory product occurs in ducts outside of the cirrus pouch. Prostate glands are not present in the Caryophyllidea (Nybelin 1922, Mackiewicz 1972, Protasova et al. 1990, Poddubnaya 2003b), monopleuroid cestodes often placed close to the Spathebothriidea.

The general pattern of the fine structures of the genital male ducts is similar to that described in lower cestodes (Davydov et al. 1994, Korneva and Davydov 2001, Korneva 2002, Poddubnaya 2002, 2003a, b). Common to all male ducts is the syncytial epithelium. The main differences concern the presence or absence of epithelial perikarya, types of apical covering, quantity of muscle layers beneath the epithelium and the extent of musculature around the cirrus sac. Cyathocephalus truncatus has the vasa efferentia with an anucleate epithelium, as described in caryophyllidean species (Davydov et al. 1994, Poddubnaya 2003b) and $D$. latum (Poddubnaya 2002). As is characteristic of all lower cestodes, $C$. truncatus has a vas deferens with large nuclei in the epithelial syncytium. The character of the nucleate epithelium of the ejaculatory duct of $C$. truncatus is similar to that of D. latum (Poddubnaya 2002), Triaenophorus nodulosus (Korneva 2002), and Archigetes sieboldi (Poddubnaya 2003b). The anucleate lining of the cirrus in $C$. truncatus has also been described from the pseudophyllidean cestodes $T$. nodulosus (Korneva 2002) and Eubothrium rugosum (Poddubnaya 2003a), and is in strong contrast with the condition of sunken cirrus nuclei in Caryophyllaeus laticeps (Davydov et al. 1994), three species of proteocephalidean cestodes (Korneva and Davydov 2001), and D. latum (Poddubnaya 2002).

Various types of cirrus microtriches have been described in cestodes (Lumsden and Specian 1980, Beveridge and Smith 1985, Jones 1989, Davydov et al. 1994, Davydov and Korneva 2002, Korneva 2002, Poddubnaya 2002, 2003b). It is postulated that these microtriches may help to maintain the cirrus in the vagina during insemination by interdigitating with vagina microtriches (Beveridge and Smith 1985, Jones 1989). The fact that in $C$. truncatus the microtriches of the distal portion of the vagina and cirrus are similar to each other lends support to that theory. Similar structures of microtriches in both cirrus and vagina have been reported in the caryophyllidean cestode Archigetes sieboldi (Poddubnaya 2003b, Poddubnaya et al. 2003). The internal lining of the cirrus in C. truncatus has small uniform cone-shaped microtriches similar to those within the cirrus of the progenetic, caryophyllidean, A. sieboldi (Poddubnaya 2003b). The presence or absence of microtriches on the cirrus, or their modification may be related to the condition under which copulation takes place (Poddubnaya 2003a), as shown by a comparison of the cirrus of E. rugosum and that of D. latum. In the case of E. rugosum, the small size of the cirrus pouch, absence of cirrus microtriches and the presence of only 


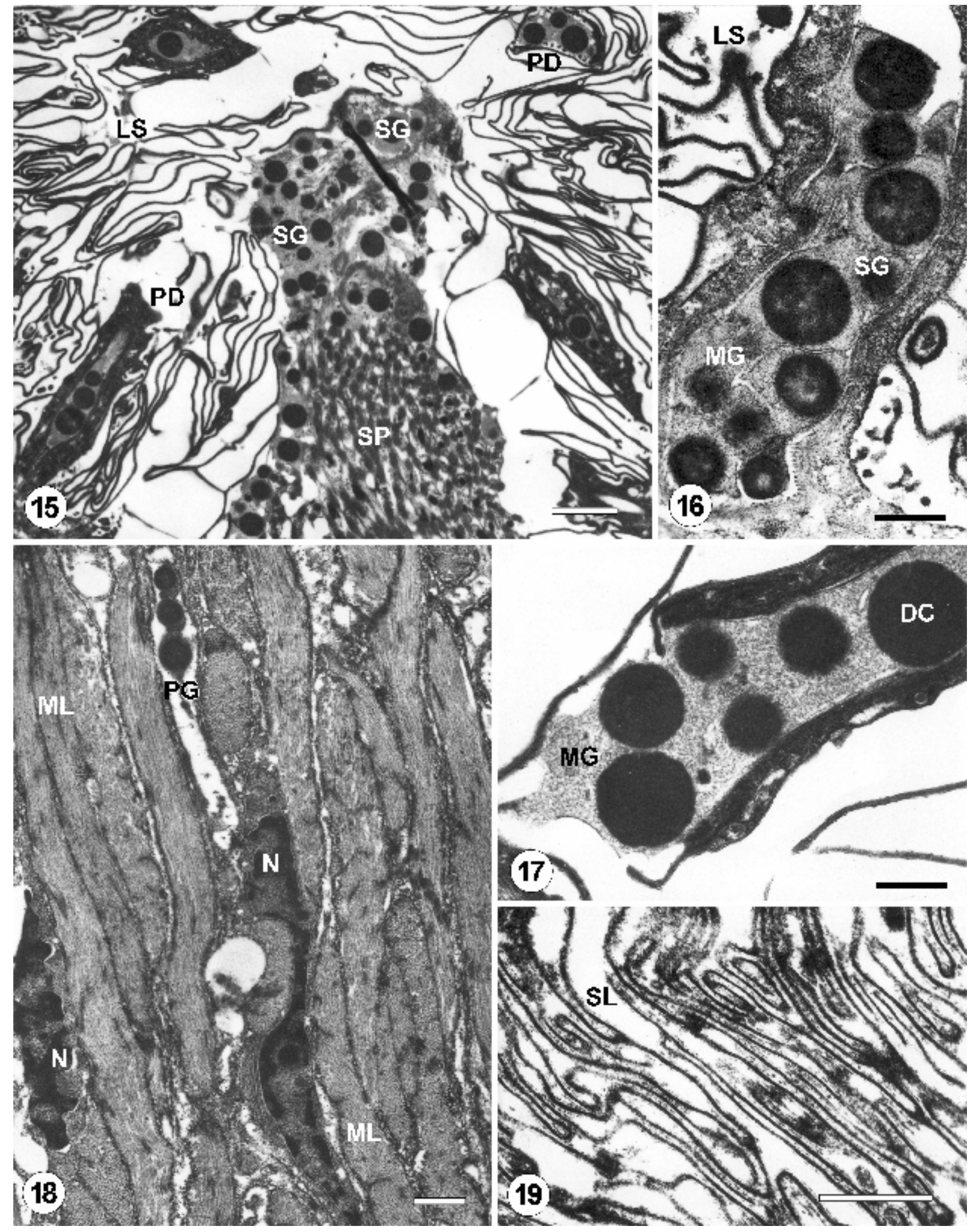

Figs. 15-19. Exit of the prostate gland secretion and cirrus pouch of Cyathocephalus truncatus. Fig. 15. Secretory granules coalesced around spermatozoa in the lumen of ejaculatory duct. Fig. 16. Prostate duct with coalesced granules. Fig. 17. The duct discharges of electron-dense cores of granules and fibrous material. Fig. 18. The muscular layers and myocytons of cirrus sac wall. Fig. 19. Sarcoplasma-like lamellae of cirrus sac myocytons. Abbreviations: DC - dense core; LS - sinuous lamellae; MG outer matrix of lower electron density of secretory granules; ML - muscle layers; N - nucleus; PD - prostate duct; PG - projection of the prostate glands; SG - secretory granules; SL - sarcoplasma-like lamellae; SP - spermatozoa. Scale bars: Fig. $15=2$ $\mu \mathrm{m}$; Figs. 16, 17, $19=0.5 \mu \mathrm{m}$; Fig. $18=1 \mu \mathrm{m}$. 


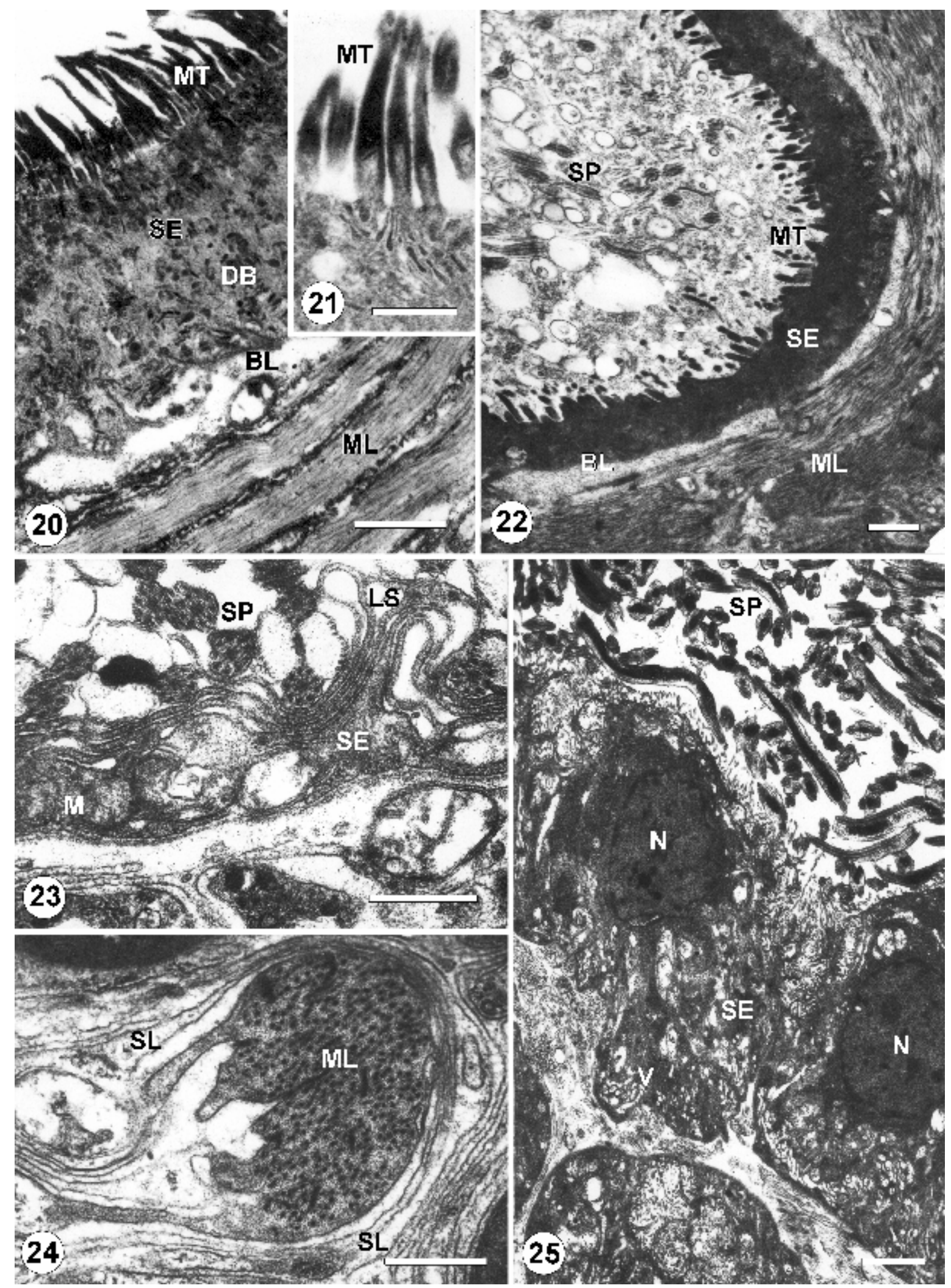

Figs. 20-25. Vagina and seminal receptacle of Cyathocephalus truncatus. Fig. 20. The distal part of vagina. Fig. 21. Microtriches of distal part of vagina. Fig. 22. The proximal part of vagina. Fig. 23. The distal cytoplasm lining of seminal receptacle. Fig. 24. Sarcoplasma-like lamellae beneath seminal receptacle wall. Fig. 25. Section through part of seminal receptacle with large nucleus. Abbreviations: BL - basal lamina; DB - dense bodies; LS - sinuous lamellae; M - mitochondrion; ML - muscle layers; MT - microtriches; N - nucleus; SE - syncytial epithelium; SL - sarcoplasma-like lamellae; SP - spermatozoa; V - vesicles. Scale bars: Figs. 20, $22=1 \mu \mathrm{m}$; Fig. $21=0.2 \mu \mathrm{m}$; Figs. $23,24=0.5 \mu \mathrm{m}$; Fig. $25=2 \mu \mathrm{m}$; 
occasional lamellae on the cirrus surface may be associated with its living in the pyloric ceaca of the burbot. These caeca are small, implying a close contact between mature parts of a strobila, thus facilitating cross-insemination. In contrast, D. latum has a large, well-developed cirrus pouch, three types of microtriches on the cirrus surface, big, hook-like microtriches on the surface of the genital atrium, and a field of receptors around the genital atrium. Such a highly developed copulatory organ may be an advantage for a species living within the large lumen of the intestine where condition for crossinsemination may not be as good.

The presence of well-developed muscle layers beneath the epithelium of the gonadoducts and within and around the cirrus sac of $C$. truncatus, combined with the extensive lamellar structure of the myocytons (20 layers) of the cirrus sac, facilitates flexibility of the long cirrus and allows for cross-insemination. Contractions of the muscular walls of the ejaculatory duct, cirrus and vagina may produce peristaltic waves along the ducts that are involved in spermatozoon ejaculation and insemination. All of these structures are well-adapted to function to insure successful sperm transfer: the numerous active prostate glands, muscular wall of cirrus pouch, well-developed muscular layers beneath the ejaculatory duct and cirrus, and long cirrus covered with the same uniform cone-shaped microtriches as within the vagina, combine with the extensive seminal recepta- cle to store a considerable mass of sperm for successful ejaculation and, probably, both self- and cross-insemination.

Study of the ultrastructure of the male reproductive ducts of $C$. truncatus has revealed that this species not only shares the structure of cirrus with the monozoic, progenetic caryophyllidean, $A$. sieboldi, but also shares the well-developed prostate glands with the polyzoic pseudophyllidean, D. latum. These data are thus congruent with the mixed results of molecular analyses, which, on the one hand, group the Spathebothriidea with the Caryophyllidea (Hoberg et al. 2001, Olson et al. 2001), on the other hand, group members of the Spathebothriidea with diphyllobothriids (Kodedová et al. 2000). Perhaps subsequent ultrastructural investigations of other members of the Spathebothriidea will help to clarify the interrelationships between the basal groups of lower tapeworms.

Acknowledgements. This study was supported by the Russian Foundation of Fundamental Research (RFFR), grant no. 0504-48250 and was made in the framework of a bilateral joint research project supported by an agreement on scientific exchange and co-operation signed by the Czech and Russian Academies of Sciences. It was supported by the Grant Agency of the Czech Republic (project no. 206/03/1317) and research project of the Institute of Parasitology, Academy of Sciences of the Czech Republic (Z60220518).

\section{REFERENCES}

BEVERIDGE I., SMITH K. 1985: An ultrastructural study of the cirrus and vagina of Phyllobothrium vagans (Cestoda: Tetraphyllidea). Z. Parasitenkd. 71: 609-616.

COIL W.H. 1970: Studies on the biology of the tapeworm Dioecocestus acotylus with emphasis on the oogenotop. Z. Parasitenkd. 33: 314-328.

DAVYDOV V.G., KORNEVA Zh.V. 2002: Structure of the copulative apparatus of Sobolevicanthus gracilis (Cestoda: Cyclophyllidea). Parazitologiya 36: 224-230. (In Russian.)

DAVYDOV V.G., PODDUBNAYA L.G., KOLESNIKOVA G.A. 1994: Ultrastructure of genital system ducts of Caryophyllaeus laticeps (Cestoda, Caryophyllidea). Parazitologiya 28: 501-509. (In Russian.)

DAVYDOV V.G., PODDUBNAYA L.G., KUPERMAN B.I. 1997: An ultrastructure of some systems of the Diplocotyle olrikii (Cestoda: Cyathocephalata) in relation to peculiarities of its life cycle. Parazitologiya 31: 132-141. (In Russian.)

FUHRMANN O. 1931: Dritte Klasse des Cladus Plathelminthes: Cestoidea. In W. Kükenthal and T. Krumbach (Eds.), Handbuch der Zoologie. Walter de Gruyter and Co., Berlin, pp. 141-416.

GIBSON D.I. 1994: Order Spathebothriidea Wardle \& McLeod, 1952. In: L.F. Khalil, A. Jones and R.A. Bray (Eds.), Keys to the Cestode Parasites of Vertebrates. CAB International, Wallingford, Oxon, pp. 15-19.
HALTON D.W., HARDCASTLE A. 1977: Ultrastructure of the male accessory ducts and prostate gland of Diclidophora merlangi (Monogenoidea). Int. J. Parasitol. 7: 393401.

HOBERG E.P., MARIAUX J., BROOKS D.R. 2001: Phylogeny among orders of the Eucestoda (Cercomeromorphae): integrating morphology, molecules and total evidence. In: D.T.J. Littlewood and R.A. Bray (Eds.), Interrelationships of the Platyhelminthes. Taylor \& Francis, London, pp. 112-126.

JONES M.K. 1989: Ultrastructure of the cirrus pouch of $\mathrm{Cyl}$ indrotaenia hickmani (Jones, 1985) (Cestoda, Nematotaeniidae). Int. J. Parasitol. 19: 919-930.

JONES M.K. 1994: Ultrastructure of the male accessory glands and sperm ducts of Cylindrotaenia hickmani (Cestoda: Cyclophyllidea). Acta Zool. 75: 269-275.

JOYEUX C.H., BAER J.G. 1961: Classe des Cestodes. In: P.-P. Grassé (Ed.), Traité de Zoologie. Tome 4, Fasc. 1. Masson, Paris, pp. 345-560.

KEARN G.C. 1998: Parasitism and the Platyhelminths. Chapman \& Hall, London, $221 \mathrm{pp}$.

KODEDOVÁ I., DOLEŽEL D., BROUČKOVÁ M., JIRKŮ M., HYPŠA V., LUKEŠ J., SCHOLZ T. 2000: On the phylogenetic positions of the Caryophyllidea, Pseudophyllidea and Proteocephalidea (Eucestoda) inferred from 18S rRNA. Int. J. Parasitol. 30: 1109-1113. 
KORNEVA Zh.V. 2002: Ultrastructural organization of reproductive system in Triaenophorus nodulosus (Cestoda, Pseudophyllidea). Zool. Zh. 81: 1432-1438. (In Russian.)

KORNEVA Zh.V., DAVYDOV V.G. 2001: Ultrastructure of male reproductive system in three proteocephalidean cestodes. Zool. Zh. 80: 921-928. (In Russian.)

LUMSDEN R.D., SPECIAN R. 1980: The morphology, histology and fine structure of the adult stage of the cyclophyllidean tapeworm Hymenolepis diminuta. In: M.P. Arrai (Ed.), Biology of the Tapeworm Hymenolepis diminuta L. Academic Press, New York, pp. 157-280.

MACKIEWICZ J.S. 1972: Caryophyllidea (Cestoidea): a review. Exp. Parasitol. 31: 417-512.

MACKIEWICZ J.S. 2003: Caryophyllidea (Cestoidea): molecules, morphology and evolution. Acta Parasitol. 48: 143154.

MacKINNON B.M., BURT M.D.P. 1984: The comparative ultrastructure of spermatozoa from Bothrimonus sturionis Duv., 1842 (Pseudophyllidea), Pseudanthobothrium hanseni Baer, 1956 (Tetraphyllidea), and Monoecocestus americanus Stiles, 1895 (Cyclophyllidea). Can. J. Zool. 62: $1059-1066$.

MARIAUX J. 1998: A molecular phylogeny of the Eucestoda. J. Parasitol. 84: 114-124.

MARIAUX J., OLSON P.D. 2001: Cestode systematics in the molecular era. In: D.T.J. Littlewood and R.A. Bray (Eds.), Interrelationships of the Platyhelminthes, Taylor \& Francis, London, pp. 127-134.

NYBELIN O. 1922: Anatomisch-systematische Studien über Pseudophyllideen. Göteborgs Kungl. Vetenkaps-och. Viterhets-Samhalles Handlingar, Fjärde Följden, 26, 228 pp.

OKAKA C.E. 2000: Maturity of the procercoid of Cyathocephalus truncatus (Eucestoda: Spathebothriidea in Gammarus pulex (Crustacea: Amphipoda) and tapeworm life cycle using the amphipod as the sole host. Helminthologia 37: $153-157$.
OLSON P.D., CAIRA J.N. 1999: Evolution of the major lineages of tapeworms (Platyhelminthes: Cestoidea) inferred from $18 \mathrm{~S}$ ribosomal DNA and elongation factor-1 $\alpha$. J. Parasitol. 85: 1134-1159.

OLSON P.D., LITTLEWOOD D.T.J., BRAY R.A., MARIAUX J. 2001: Interrelationships and evolution of the tapeworms (Platyhelminthes: Cestoda). Mol. Phylog. Evol. 19: 443-467.

PODDUBNAYA L.G. 2002: Ultrastructure of reproductive ducts in Diphyllobothrium latum (Cestoda, Pseudophyllidea) males. Zool. Zh. 81: 394-405. (In Russian.)

PODDUBNAYA L.G. 2003a: Structure of reproductive system of the amphicotylide cestode Eubothrium rugosum (Cestoda, Pseudophyllidea). J. Evol. Biochem. Physiol. 39: 345-355.

PODDUBNAYA L.G. 2003b: Ultrastructure of reproductive organs and ducts in the progenetic species Archigetes sieboldi (Cestoda, Caryophyllidea). Zool. Zh. 82: 1038 1050. (In Russian.)

PODDUBNAYA L.G., MACKIEWICZ J.S., KUPERMAN B.I. 2003: Ultrastructure of Archigetes sieboldi (Cestoda: Caryophyllidea): relationship between progenesis, development and evolution. Folia Parasitol. 50: 275-292.

PROTASOVA E.N., KUPERMAN B.I., ROITMAN V.A., PODDUBNAYA L.G. 1990: [Caryophyllideans of the fauna of the USSR.] Izd. Nauka, Moskva, 238 pp. (In Russian.)

PROTASOVA E.N., ROYTMAN V.A. 1995: [Cyathocephalates, tapeworm helminthes of marine and freshwater fish (Cestoda: Pseudophyllidea: Cyathocephalata).] [Essentials of Cestodology. Vol. 12.] Institute of Parasitology RAN, Moskva, 134 pp. (In Russian.)

WARDLE R.A., McLEOD J.A. 1952: The Zoology of Tapeworms. The University of Minnesota Press, Minneapolis, $780 \mathrm{pp}$.

Accepted 7 September 2004 